\title{
Evaluación de las proteínas hidrolizadas del lactosuero como fuente de nitrógeno en la fermentación láctica de la lactosa
}

\author{
Evaluation of hydrolyzed whey proteins as a nitrogen \\ source in the lactic fermentation of lactose
}

\section{Avaliação de proteínas hidrolisadas de soro como fonte de nitrogênio na fermentação láctica de lactose}

\author{
Paula Andrea Duarte-Manchego; Juan Carlos González-Téllez; Carlos Jesús Muvdi-Nova* \\ Centro de Investigación en Ciencia y Tecnología de Alimentos CICTA, Escuela de Ingeniería Química. Universidad \\ Industrial de Santander (UIS), Cra. 27 Calle 9, Bucaramanga, Colombia. \\ *cjmuvdi@uis.edu.co
}

Fecha recepción: 11 de junio de 2019 Fecha aceptación: 10 de octubre de 2019

\begin{abstract}
Resumen
Se evaluó una estrategia para el aprovechamiento y la valorización de las proteínas del lactosuero resultante del proceso de obtención de cuajada a partir de leche ácida. Se plantean las etapas de precipitación (desnaturalización térmica y ácida) e hidrólisis enzimática, para su posterior uso como fuente de nitrógeno en la fermentación de la lactosa para la obtención de ácido láctico. Se encontraron las mejores condiciones de $\mathrm{pH}$ y T en la hidrólisis, 10 y $60^{\circ} \mathrm{C}$, respectivamente, evidenciando un tamaño molecular para los hidrolizados inferior a 6,5 kDa. Finalmente, fueron utilizados en la fermentación láctica de la lactosa con Lactobacillus casei ATCC 393, a concentraciones de $1 \%$ p y $7 \%$ p. Se realizaron también pruebas utilizando extracto de levadura al $1 \%$ como referencia. El crecimiento microbiano $\left(2,1^{*} 10^{9} \mathrm{y}\right.$ $\left.1,9^{*} 10^{9} \mathrm{UFC} / \mathrm{cm}^{3}\right)$, el rendimiento producto/sustrato $(0,78$ y $0,76 \mathrm{~g} / \mathrm{g})$ y la productividad $(0,41$ y $0,30 \mathrm{~g} /$ $\mathrm{dm}^{3} . \mathrm{h}$ ) fueron similares para los medios con extracto de levadura e hidrolizado al $1 \% \mathrm{P}$, respectivamente, mientras que el hidrolizado al 7 \% mostró cierta inhibición, que podría estar relacionada con un alto contenido de nitrógeno total en el medio y que se vio reflejada en las variables de respuesta mencionadas anteriormente $\left(9,5^{*} 10^{8} \mathrm{UFC} / \mathrm{cm}^{3}, 0,53 \mathrm{~g} / \mathrm{g}\right.$ y $\left.0,18 \mathrm{~g} / \mathrm{dm}^{3} . \mathrm{h}\right)$.
\end{abstract}

Palabras clave: Hidrolizados; Proteína del Lactosuero; Fermentación; Lactobacillus Casei ATCC 393; Ácido Láctico; Extracto de Levadura.

\begin{abstract}
It was evaluated a strategy for the use and valorization of whey proteins obtained from curd process from acid milk. It is proposed the stages of precipitation (thermal and acid denaturalization) and enzymatic hydrolysis, to be used as a nitrogen source in the fermentation of lactose for the production of lactic acid. $\mathrm{pH}$ of 10 and $60^{\circ} \mathrm{C}$ were the best hydrolysis conditions. Hydrolysates with molecular sizes lower than 6.5 $\mathrm{kDa}$ were obtained at those conditions. Finally, the hydrolysates were used in the fermentation of lactose with Lactobacillus casei ATCC 393, in concentrations of $1 \% \mathrm{w}$ and $7 \% \mathrm{w}$. Fermentations using a medium with $1 \% \mathrm{w}$ of yeast extract were also carried out as a reference. The microbial growth $\left(2.1^{*} 10^{9}\right.$ y $1.9^{*} 10^{9}$ $\left.\mathrm{CFU} / \mathrm{cm}^{3}\right)$, the product $/$ substrate yield $(0.78$ and $0.76 \mathrm{~g} / \mathrm{g})$ and productivity $\left(0.41 \mathrm{y} 0.30 \mathrm{~g} / \mathrm{dm}^{3} . \mathrm{h}\right)$ were similar for the yeast extract and hydrolysate mediums at $1 \% \mathrm{w}$, while the hydrolysate at $7 \% \mathrm{w}$ showed certain inhibition in the medium which was reflected in the response variables mentioned above $\left(9.5^{*} 10^{8}\right.$ UFC $/ \mathrm{cm}^{3}, 0.53 \mathrm{~g} / \mathrm{g}$ and $\left.0.18 \mathrm{~g} / \mathrm{dm}^{3} . \mathrm{h}\right)$.
\end{abstract}

Keywords: Hydrolysates; Whey Protein; Fermentation; Lactobacillus Casei ATCC 393; Lactic Acid; Yeast Extract. 


\section{Resumo}

Uma estratégia para a utilização e valorização das proteínas do soro resultantes do processo de obtenção de coalhada a partir do leite ácido foi avaliada. Os estágios de precipitação (desnaturação térmica e ácida) e hidrólise enzimática são propostos, para sua posterior utilização como fonte de nitrogênio na fermentação de lactose para a produção de ácido lático e lactato. As melhores condições de $\mathrm{pH}$ e $\mathrm{T}$ foram encontradas na hidrólise, 10 e $60^{\circ} \mathrm{C}$, respectivamente, evidenciando um tamanho molecular para os hidrolisados abaixo de 6,5 kDa. Finalmente, eles foram usados na fermentação do ácido láctico com Lactobacillus casei ATCC 393, nas concentrações de $1 \%$ p e 7 \%p. Os testes também foram realizados usando $1 \% \mathrm{p} / \mathrm{p}$ de extrato de levedura como referência. Crescimento microbiano $\left(2,1^{*} 10^{9}\right.$ e $1,9^{*} 10^{9}$ $\left.\mathrm{UFC} / \mathrm{cm}^{3}\right)$, rendimento produto/ substrato $(0,78$ e $0,76 \mathrm{~g} / \mathrm{g})$ e produtividade $\left(0,41\right.$ e $\left.\left.0,30 \mathrm{~g} / \mathrm{dm}^{3} \cdot \mathrm{h}\right)\right)$ foram similares para os meios com extrato de levedura e $1 \%$ de hidrolisado, respectivamente, enquanto 0 hidrolisado de $7 \%$ apresentou alguma inibição, o que pode estar relacionado a um alto teor de nitrogênio total no meio e que se refletiu no variáveis de resposta mencionadas acima $\left(9,5^{\star} 10^{8} \mathrm{UFC} / \mathrm{cm}^{3}, 0,53 \mathrm{~g} /\right.$ ge $\left.0,18 \mathrm{~g} / \mathrm{dm}^{3} . \mathrm{h}\right)$.

Palavras-chave: Hidrolisados; Proteína do Soro do Leite; Fermentação; Lactobacillus Casei ATCC 393; Ácido Lático; Extrato de Levedura.

\section{Introducción}

El ácido láctico es un compuesto higroscópico, orgánico, incoloro e inodoro, de baja volatilidad, utilizado en procesos alimenticios, farmacéuticos y químicos [1]. Se proyecta que su mercado mundial alcance una tasa de crecimiento anual compuesta de $16,7 \%$, en el periodo 2017-2021 (Business Wire Inc., 2017). En el caso de Colombia, los datos del Departamento Administrativo Nacional de Estadística (DANE) muestran una producción nacional casi nula, junto con una marcada tendencia de incremento en la importación del ácido láctico y de sus sales (lactatos) [2]. El 90 $\%$ de su producción a nivel mundial se lleva a cabo por vía biotecnológica mediante mecanismo fermentativo, el cual tiene la ventaja de formar uno de sus dos isómeros ópticos, (dextrógiro $\mathrm{D}(-)$ o levógiro $L(+)$ ), dependiendo principalmente del microorganismo seleccionado y de las condiciones dispuestas en el medio de fermentación [1,3]. El $\mathrm{L}(+)$ ácido láctico es deseable para aplicaciones de grado alimenticio y para la producción de plásticos biodegradables [4].

Las bacterias del género Lactobacillus son de amplio uso para este tipo de procesos fermentativos gracias a su capacidad de metabolizar monosacáridos y disacáridos como la glucosa y la lactosa con buenos rendimientos y productividades. Sin embargo, estos microorganismos, requieren como fuente de nitrógeno complejos nutricionales, ricos en aminoácidos y vitaminas que estimulen su crecimiento y por ende la producción de ácido láctico. Este aspecto juega un papel fundamental en la productividad y en la factibilidad económica del proceso, por lo cual su adecuada selección es muy importante [5]. En la literatura se ha reportado el uso de extracto de levadura, [6-8], debido a que es una fuente de nitrógeno de fácil asimilación, que conduce así, a productividades más altas, gracias al contenido de purinas, pirimidinas y vitamina B [9]. Sin embargo, al considerar una aplicación de tipo industrial, su elevado costo disminuye la rentabilidad del proceso, razón por la cual en los últimos años se han estudiado fuentes de mayor disponibilidad y bajo costo que conduzcan a un proceso competitivo y sostenible.

Una de las fuentes de nitrógeno alternativas con potencial uso en procesos fermentativos puede obtenerse mediante el aprovechamiento de la fracción proteica del lactosuero; subproducto obtenido durante la elaboración del queso. Se estima que se producen $9 \mathrm{dm}^{3}$ de lactosuero por cada $\mathrm{kg}$ de queso, conteniendo alrededor del $20 \%$ de las proteínas de la leche, entre las que se encuentra la $\beta$-lactoglobulina $(\beta-L g)$, la $\alpha$-lactoalbúmina $(\alpha-L a)$, la albúmina sérica bovina (BSA) y las inmunoglobulinas (Ig) [10]. Las propiedades más relevantes de las proteínas del lactosuero se presentan en la Tabla 1. A pesar de su contenido nutricional, el lactosuero ha sido considerado un residuo y al ser vertido directamente a fuentes hídricas resulta en un serio problema ambiental, motivo por el cual se ha venido buscando nuevas y mejores alternativas de uso [11]. 
Tabla 1. Propiedades principales de las proteínas del lactosuero.

\begin{tabular}{ccccc}
\hline Propiedad fisicoquímica & $\boldsymbol{\beta}$ - $\mathbf{L g}$ & $\boldsymbol{\alpha}$-La & BSA & Ig \\
\hline Peso molecular $(\mathrm{kDa})$ & 18,3 & 14,2 & 66,4 & $\geq 146$ \\
Punto isoeléctrico & 5,2 & $4,2-4,5$ & $4,7-4,9$ & $5,5-8,3$ \\
Concentración en el lactosuero $\left(\mathrm{g} / \mathrm{dm}^{3}\right)$ & $2-4$ & $1-1,5$ & 0,4 & $0,4-1$ \\
\hline
\end{tabular}

Modificado de [10].

De esta manera, el objetivo del presente trabajo consistió en estudiar una estrategia de aprovechamiento del lactosuero, mediante la separación por desnaturalización térmica y ácida de sus proteínas (requesón), para su posterior hidrólisis enzimática a las condiciones más favorables de $\mathrm{pH}$ y temperatura, y finalmente evaluar su utilización como fuente de nitrógeno en la fermentación láctica de la lactosa utilizando Lactobacillus casei (L.casei) ATCC 393.

\section{Metodología}

\section{Desnaturalización térmica y ácida}

Se utilizó lactosuero ácido proveniente de las actividades de producción de queso hilado del Sena C.A.S.A. Piedecuesta (Santander, Colombia) y se sometió a tratamiento térmico y ácido a 93 ${ }^{\circ} \mathrm{C} \mathrm{y} \mathrm{pH} \mathrm{4,4} \mathrm{durante} 40 \mathrm{~min}$ [12]. El lactosuero clarificado fue drenado, mientras que el requesón obtenido fue recuperado mediante filtración en tela tipo dril de 70 hilos/pulgada en urdimbre y 42 hilos/ pulgada en trama.

\section{Hidrólisis}

Se realizó un diseño experimental aleatorio, con tres niveles, analizando la influencia del $\mathrm{pH}$ y de la temperatura sobre el grado de hidrólisis $(\mathrm{DH})$ con tres niveles para cada variable: 8,9 , y 10; 55 ${ }^{\circ} \mathrm{C}, 60^{\circ} \mathrm{C}$ y $65^{\circ} \mathrm{C}$, respectivamente (definidos de acuerdo a intervalos de trabajo indicados en la ficha técnica de la enzima). Se empleó la proteasa líquida comercial Gelzyme L500@ (PROENZIMAS S.A.) y como sustrato el requesón obtenido en la etapa previa, diluido en agua destilada para alcanzar un contenido de proteína de $4,2 \% \mathrm{p} / \mathrm{v}$, con una relación enzima sustrato del $1 \% \mathrm{p}$, en un volumen de trabajo de $200 \mathrm{~cm}^{3}$ y una duración de 90 min $[13,14]$.

El grado de hidrólisis (DH) fue determinado mediante la técnica $\mathrm{pH}$-state $[15,16]$, que relaciona el $\mathrm{DH}$ con el volumen de $\mathrm{NaOH}$ utilizado para mantener el $\mathrm{pH}$ de trabajo constante, según la siguiente ecuación:

$$
D H \%=\frac{B * N_{B}}{M_{P} * h_{t o t} * \alpha} * 100
$$

Donde, $B$ representa el volumen acumulado de $\mathrm{NaOH}\left(\mathrm{cm}^{3}\right) ; N_{B}$ la concentración de $\mathrm{NaOH}(2 \mathrm{~N})$; $M p$ la masa total de proteína hidrolizada $(\mathrm{g}) ; h_{t o t} \mathrm{el}$ número total de enlaces peptídicos, tomado como $8,8 \mathrm{meq} / \mathrm{g}$ para proteína del lactosuero [16], $\alpha(\mathrm{pH}$, pKa) el grado de disociación de grupos amino liberados durante la hidrólisis. Se tomó 7,1 como el pKa promedio para proteínas del lactosuero [15] y $\alpha(\mathrm{pH}, \mathrm{pKa})$ fue determinado mediante la ecuación 2 .

$$
\alpha=\frac{10^{p H-p K a}}{1+10^{p H-p K a}}
$$

Con las mejores condiciones de $\mathrm{pH}$ y Tidentificadas, se realizaron las hidrólisis hasta estabilización del $\mathrm{DH}$. La inactivación de la enzima se realizó a $95{ }^{\circ} \mathrm{C}$ durante $15 \mathrm{~min}$. Los hidrolizados fueron caracterizados en \% de nitrógeno total (A.O.A.C. 991,20 ), \% de nitrógeno amino (Método Kjeldahl sin digestión), determinación del tamaño de las especies proteicas mediante electroforesis tricina SDS-PAGE al $16 \%$ de acrilamida bisacrilamida AB-3 y tinción de Coomassie [16]. Los hidrolizados se mantuvieron en congelación a $-20^{\circ} \mathrm{C}$ para su posterior uso como fuente de nitrógeno en la fermentación láctica de lactosa.

\section{Fermentación}

Se utilizó la cepa Lactobacillus casei (L. casei) ATCC 393 (Microbilogics $®$ ) en presentación kwik stick, activada en agar MRS (Merck®), e incubada a $37^{\circ} \mathrm{C}$ en placas de Petri durante $24 \mathrm{~h}$ y luego conservadas a $4{ }^{\circ} \mathrm{C}$ para su posterior uso.

Se transfirió una azada del microorganismo activado a $200 \mathrm{~cm}^{3}$ de medio de precultivo con la siguiente composición: lactosa (Merck®) $44 \mathrm{~g} / \mathrm{dm}^{3}$; extracto de levadura (Merck®) $10 \mathrm{~g} / \mathrm{dm}^{3} ; \mathrm{KH}_{2} \mathrm{PO}_{4}$ (Merck®) 0,5 g/dm ${ }^{3} ; \mathrm{K}_{2} \mathrm{HPO}_{4}$ (Merck®) $0,5 \mathrm{~g} / \mathrm{dm}^{3}$; $\mathrm{MnSO}_{4} \cdot \mathrm{H}_{2} \mathrm{O}$ (Merck®) $0,05 \mathrm{~g} / \mathrm{dm}^{3} ; \mathrm{MgSO}_{4} \cdot 7 \mathrm{H}_{2} \mathrm{O}$ (Merck®) 0,2 $\mathrm{g} / \mathrm{dm}^{3}$. El tiempo de incubación fue cercano a las $12 \mathrm{~h}$ y correspondió al tiempo de 
crecimiento del microorganismo para garantizar una población de entre $10^{6}$ y $10^{8} \mathrm{UFC} / \mathrm{cm}^{3}$ (Unidades Formadoras de Colonia por centímetro cúbico).

Las fermentaciones se realizaron por duplicado, en modo de operación batch durante $96 \mathrm{~h}$ en matraces Erlenmeyer de $500 \mathrm{~cm}^{3}$ (volumen de trabajo de
$200 \mathrm{~cm}^{3}$ ), a una temperatura de $37^{\circ} \mathrm{C}, 130 \mathrm{rpm}$ (agitación orbital), sin control de $\mathrm{pH}(\mathrm{pH}$ inicial de $6,5)$, en tres medios de fermentación distintos con la misma concentración de lactosa y cofactores $\left(\mathrm{KH}_{2} \mathrm{PO}_{4}, \mathrm{~K}_{2} \mathrm{HPO}_{4}, \mathrm{MnSO}_{4} \cdot \mathrm{H}_{2} \mathrm{O}, \mathrm{MgSO}_{4} \cdot 7 \mathrm{H}_{2} \mathrm{O}\right)$, pero con diferentes características de la fuente de nitrógeno como se muestra en la Tabla 2.

Tabla 2. Contenidos de la fuente de nitrógeno en los medios de fermentación (\% en base seca).

\begin{tabular}{cccc}
\hline Fuente de nitrógeno [\%p/p] & Medio 1 & Medio 2 & Medio 3 \\
\hline Extracto de levadura & $1 \%$ & - & - \\
Hidrolizado de proteína del lactosuero & - & $1 \%$ & $7 \%$ \\
\hline
\end{tabular}

Fuente: Elaboración propia

El crecimiento microbiano se determinó mediante conteo de UFC y medición de la densidad óptica (D.O.) a $660 \mathrm{~nm}$. El cálculo de la velocidad específica de crecimiento máxima ( $\mu$ máx) se realizó mediante la estimación de la pendiente de la sección lineal de la gráfica de $\operatorname{Ln}\left(\mathrm{N} / \mathrm{N}_{0}\right)$ vs tiempo, siendo $\mathrm{N}$ las $\mathrm{UFC} / \mathrm{cm}^{3}$ en un tiempo dado y $\mathrm{N}_{0}$ las UFC/ $/ \mathrm{cm}^{3}$ iniciales. El caldo de fermentación obtenido se caracterizó en cuanto a concentración de ácido láctico y lactosa por HPLC, empleando una columna Coregel $107 \mathrm{H}$ acoplada a un equipo UFLC LC 20AD (Shimadzu), seguida de un detector de índice de refracción RID-10A. El equipo operó en modo isocrático a $80^{\circ} \mathrm{C}$, con flujo de $0,6 \mathrm{~cm}^{3} / \mathrm{min}$. La fase móvil empleada fue ácido sulfúrico $8 \mathrm{mM}$, con tiempo de análisis de $25 \mathrm{~min}$. Adicionalmente, se hizo seguimiento al $\mathrm{pH}$ durante el transcurso de las fermentaciones.

El cálculo del rendimiento $(\mathrm{Y})$ y de la productividad (P) se realizó mediante las Ecuaciones 3 y 4 , respectivamente.

$$
\begin{gathered}
\Upsilon=\frac{g_{\text {A.láctico producido }}}{g_{\text {Lactosa consumida }}} \\
\mathrm{P}=\frac{g_{\text {A.láctico producido }}}{d m^{3} \cdot h}
\end{gathered}
$$

\section{Resultados y discusión}

\section{Desnaturalización e hidrólisis de las proteínas del lactosuero}

La caracterización del requesón obtenido en la etapa de desnaturalización térmica y ácida de las proteínas del lactosuero se muestra en la tabla 3.

En la figura 1, se muestra el \%DH de proteínas de lactosuero a los diferentes niveles de temperatura y $\mathrm{pH}$ analizados.

Tabla 3. Análisis bromatológico del requesón obtenido en la etapa de desnaturalización de las proteínas del lactosuero.

\begin{tabular}{cc}
\hline Análisis & [\%p/v] \\
\hline Humedad & 81,61 \\
Materia seca & 18,39 \\
Proteína & 11,23 \\
Ceniza & 0,57 \\
Grasa & ${ }^{*}$ DLD \\
Carbohidratos totales & 6,58 \\
\hline
\end{tabular}

Fuente: Elaboración propia. *Debajo del límite de detección 
a)

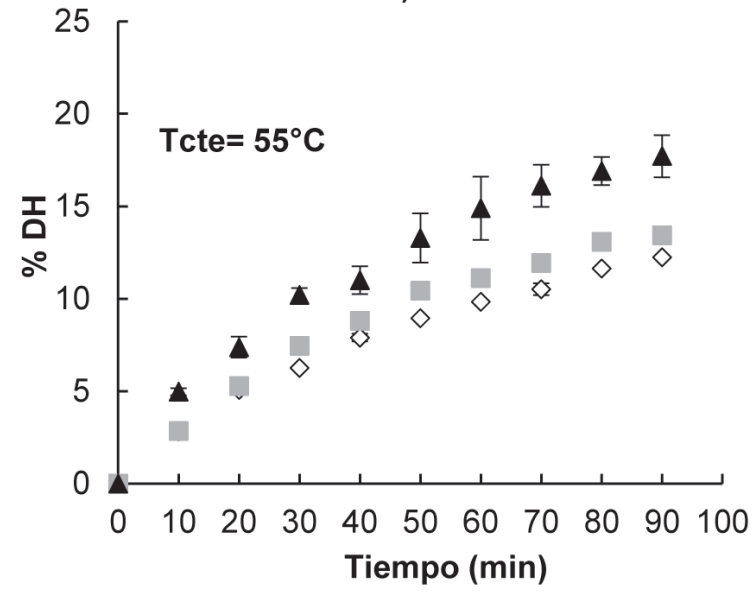

b)

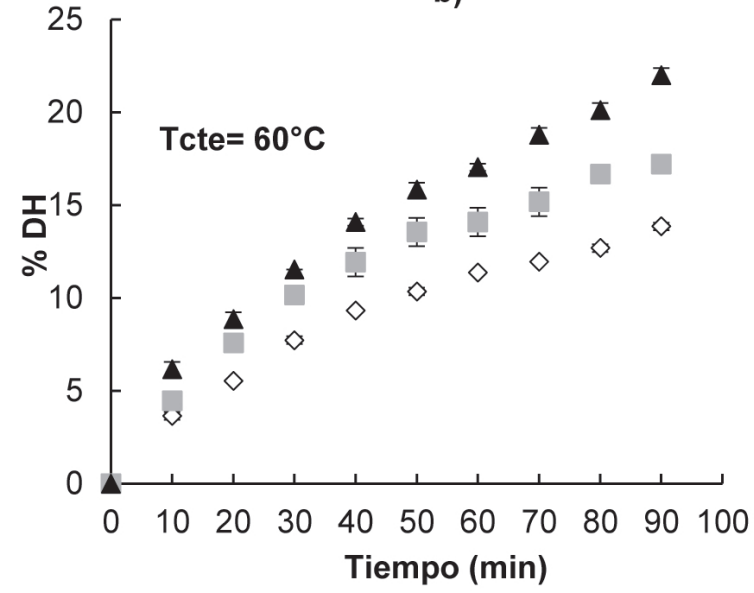

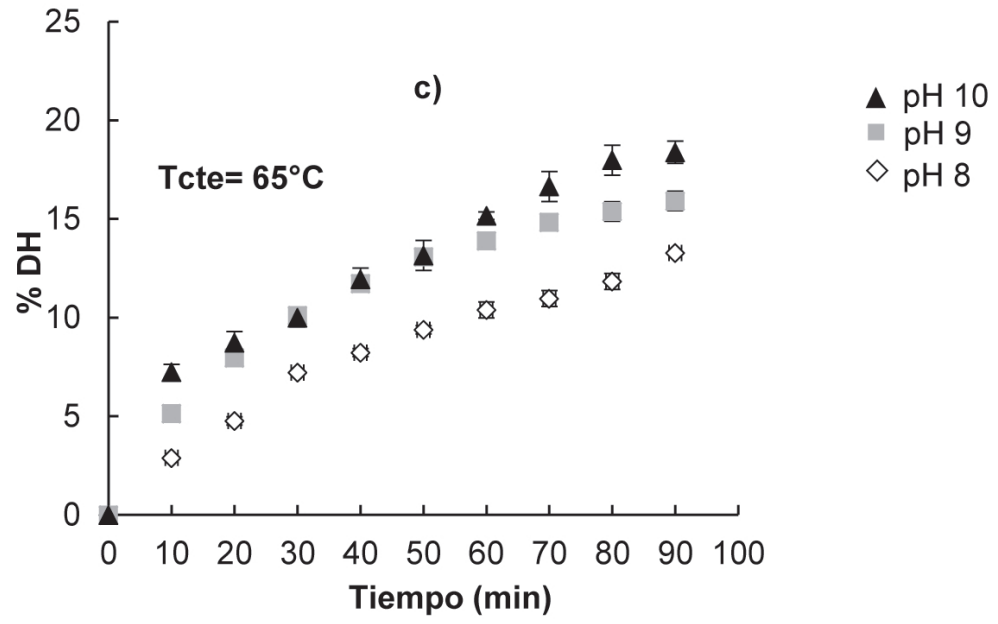

Figura 1. Comportamiento del $\mathrm{DH}$ en el tiempo para las siguientes condiciones del medio: $\mathrm{pH}$ de 8,9 y 10 y temperaturas de a) $55^{\circ} \mathrm{C}$, b) $60^{\circ} \mathrm{C}$ y c) $65^{\circ} \mathrm{C}$. Fuente: Elaboración propia.

Se observa la curva del grado de hidrólisis de forma creciente con una tendencia a estabilizarse para los diferentes valores de $\mathrm{pH}$ y temperatura. Dicho comportamiento también se ha encontrado en la literatura para otras proteasas como la Tripsina, la Papaína, la Pancreatina y la Flavourzyme, la Alcalasa, la Neutrasa, entre otras [14, 18, 19, 20]. Se realizó un análisis estadístico del diseño factorial planteado en el software Minitab ${ }^{\circledR} 16$, encontrando diferencias significativas para los dos efectos analizados, $\mathrm{pH}$ y $\mathrm{T}$, con $\mathrm{p}$-valores $<0,006$ en ambos casos. De forma general, se evidenció mayor grado de ruptura de enlaces peptídicos a $\mathrm{pH}$ de 10 , mientras que a $60^{\circ} \mathrm{C}$ fue la mejor condición,

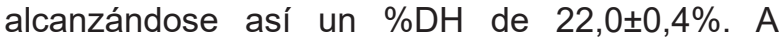
resaltar la facilidad para duplicar las hidrólisis a las diferentes condiciones evaluadas, obteniendo curvas cinéticas similares bajo las mismas condiciones de operación.

Por otro lado, se observaron cambios en la apariencia del requesón antes y después de la hidrólisis, para cada una de las condiciones experimentales evaluadas. El requesón diluido antes de la hidrólisis presentaba un color blanco (similar al de la leche), mientras que durante el transcurso de la hidrólisis $\left(a 60^{\circ} \mathrm{C}, \mathrm{pH} 10\right)$ y de la desactivación enzimática $\left(95^{\circ} \mathrm{C}\right.$ durante $15 \mathrm{~min}$ ) tomó un color ámbar, muy similar al que se obtiene al preparar una solución de extracto de levadura y esterilizar en autoclave a $125^{\circ} \mathrm{C}$ durante $15 \mathrm{~min}$. Este cambio de color se presenta por dos razones: la aparición de especies proteicas de diferentes 
tamaños moleculares $(\mathrm{DH})$ y por la pérdida de las estructuras de orden superior (desnaturalización de las proteínas) [18].

En la figura 2 se muestra la curva de evolución del $\mathrm{DH}$, trabajando a un $\mathrm{pH}$ de 10 y a $60^{\circ} \mathrm{C}$ hasta alcanzar su estabilización, logrando un \%DH de $30,4 \pm 0,9$ a los $300 \mathrm{~min}$.

Este valor es alto, al compararlo con otros estudios de hidrólisis de lactosuero crudo, como el reportado en Coelho et al. [13], en el que se emplea Pancreatina y Papaína como enzimas. En dicho estudio la hidrólisis se estabilizó durante $240 \mathrm{~min}$, logrando un \%DH no mayor a $24 \%$. Este resultado contrasta con Zheng et al. [21], en el que se emplea concentrado de proteína (WPC) a una concentración de $78 \%$ y Alcalasa, obteniendo $30 \%$ de $\mathrm{DH}$ a los $180 \mathrm{~min}$. Se deduce que estas diferencias se deben a varios factores, en primer lugar, al sustrato, el cual fija la disposición en que se encuentran las proteínas y su concentración y, en segundo lugar, la enzima utilizada [22].

Por otra parte, en la tabla 3 , se muestra la determinación del \% de nitrógeno total y el nitrógeno amino de los hidrolizados antes y después del hidrólisis, y la comparación con el \% de nitrógeno total y nitrógeno amino determinado para el extracto de levadura. En ella se evidencia una menor disposición de nitrógeno amino (\%AN) por parte del hidrolizado, pero se encuentra similitud entre los porcentajes de nitrógeno total.

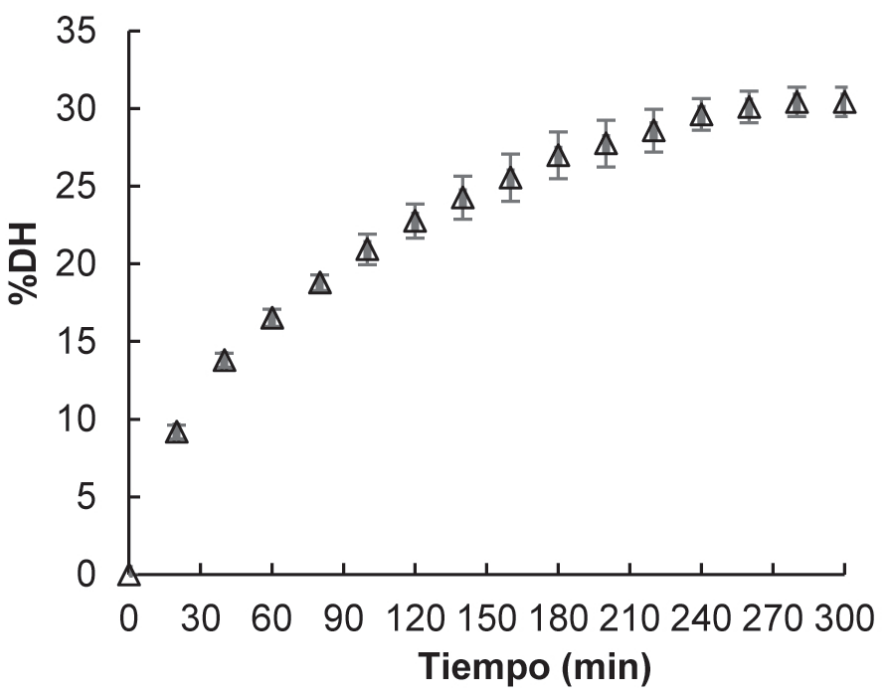

Figura 2. Curva de evolución del grado de hidrólisis. Fuente: Elaboración propia

Tabla 3. Porcentaje de nitrógeno amino y nitrógeno total en base seca durante la hidrólisis de las proteínas del lactosuero (WP) y del extracto de levadura comercial.

\begin{tabular}{ccccc}
\hline Medio & $\begin{array}{c}\text { Extracto de } \\
\text { levadura }\end{array}$ & $\begin{array}{c}\text { Requesón previo a } \\
\text { la hidrólisis }\end{array}$ & $\begin{array}{c}\text { Hidrolizado a } \\
\text { los } \mathbf{1 5 0} \text { min }\end{array}$ & $\begin{array}{c}\text { Hidrolizado a los } \mathbf{3 0 0} \text { min } \\
\text { (tiempo de estabilización) }\end{array}$ \\
\hline $\begin{array}{c}\text { Nitrógeno } \\
\text { amino (\%NA) }\end{array}$ & 4,79 & 0,35 & 0,53 & 0,54 \\
$\begin{array}{c}\text { Nitrógeno total } \\
\text { (\%NT) }\end{array}$ & 10,64 & 9,35 & 9,34 & 9,34 \\
$\frac{\% \mathbf{N A}}{\% \mathbf{N T}}$ & 0,45 & 0,037 & 0,056 & 0,057 \\
\hline
\end{tabular}

Fuente: elaboración propia. 
En los primeros 150 min de hidrólisis, la velocidad de reacción es mayor dando como resultado más liberación de nitrógeno durante este tiempo, sin embargo, a los 300 min estos valores muestran estabilización. Según Prieto [20], una menor relación AN/TN por parte del hidrolizado, sugiere que la especie proteica al finalizar la hidrólisis tiene mayor tamaño molecular a la encontrada en el extracto de levadura.

En la figura 3 se muestran los electroferogramas obtenidos mediante la técnica tricina-SDS PAGE para: el requesón previo a la hidrólisis (figura 3.a), el hidrolizado a los 150 min (figura 3.b), el hidrolizado a los 300 min (figura 3.c) y el marcador de proteínas usado como patrón para establecer el tamaño molecular de cada especie (figura 3.d). El rango de tamaños moleculares fijado por el patrón empleado permitió la identificación de especies con un tamaño entre 66,0 y $6,5 \mathrm{kDa}$. En cada una de las figuras, se indica el porcentaje o abundancia de la especie inyectada en cada carril junto a su respectivo peso molecular.

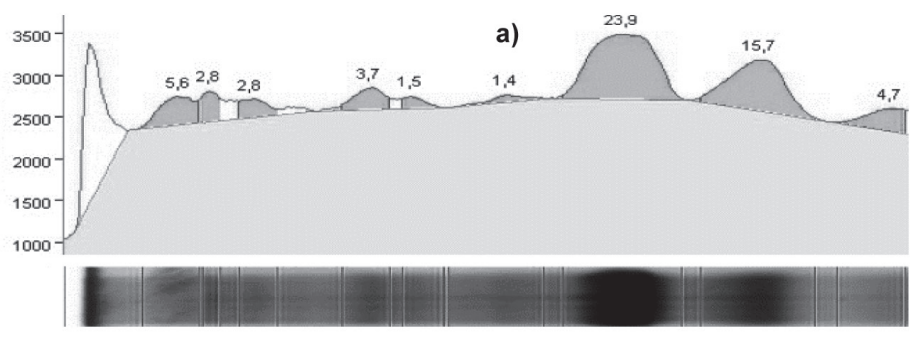

\begin{tabular}{ccc}
\hline $\begin{array}{c}\text { \# de } \\
\text { bandas }\end{array}$ & $\begin{array}{c}\text { \% banda } \\
\text { en el } \\
\text { carril }\end{array}$ & $\begin{array}{c}\text { Peso } \\
\text { molecular } \\
\text { kDa }\end{array}$ \\
\hline 1 & 5,6 & 66,0 \\
2 & 2,8 & 62,0 \\
3 & 2,8 & 54,3 \\
4 & 3,7 & 35,1 \\
5 & 1,5 & 31,0 \\
6 & 1,4 & 24,2 \\
7 & 23,9 & 18,3 \\
8 & 15,7 & 13,5 \\
9 & 4,7 & 7,5 \\
\hline
\end{tabular}

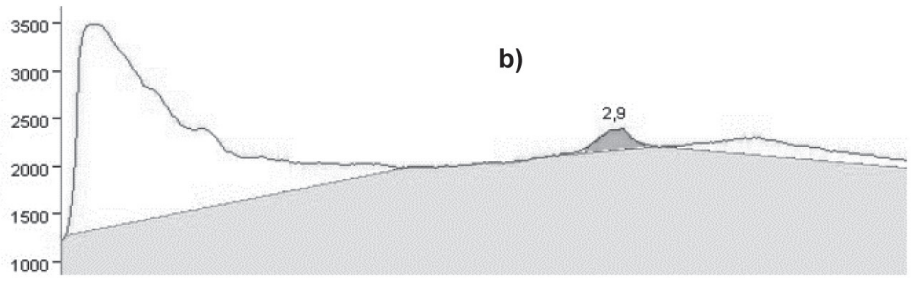

\begin{tabular}{ccc}
\hline $\begin{array}{c}\text { \# de } \\
\text { bandas }\end{array}$ & $\begin{array}{c}\text { \% banda } \\
\text { en el } \\
\text { carril }\end{array}$ & $\begin{array}{c}\text { Peso } \\
\text { molecular } \\
\mathbf{k D a}\end{array}$ \\
\hline 1 & 2,9 & 18,3 \\
\hline
\end{tabular}

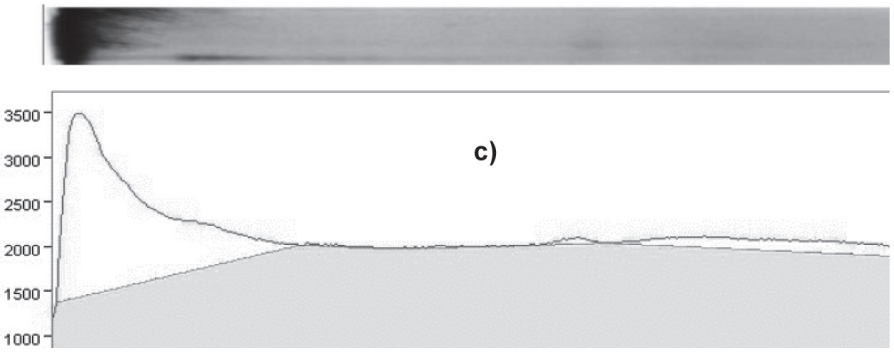

\begin{tabular}{ccc}
\hline $\begin{array}{c}\text { \# de } \\
\text { bandas }\end{array}$ & $\begin{array}{c}\text { \% banda } \\
\text { en el } \\
\text { carril }\end{array}$ & $\begin{array}{c}\text { Peso } \\
\text { molecula } \\
\mathbf{k D a}\end{array}$ \\
\hline 0 & 0 & $<6,5$ \\
\hline
\end{tabular}

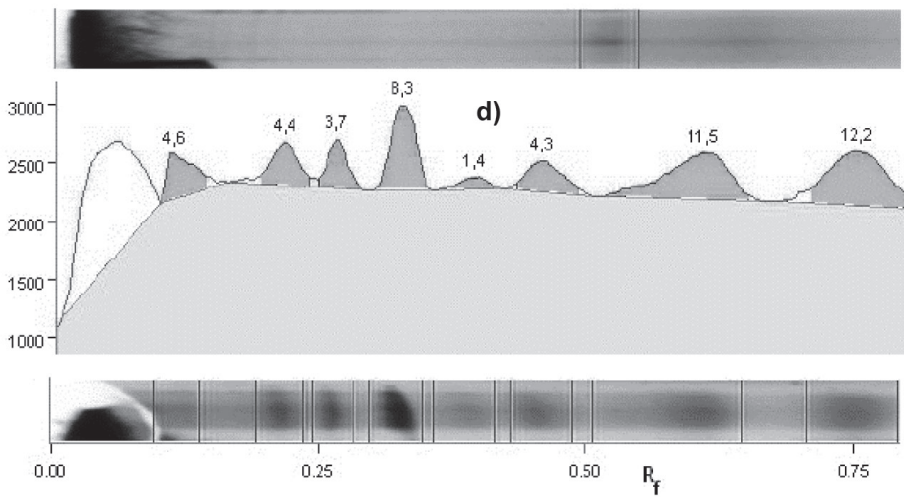

\begin{tabular}{ccc}
\hline $\begin{array}{c}\text { \# de } \\
\text { bandas }\end{array}$ & $\begin{array}{c}\% \text { banda } \\
\text { en el } \\
\text { carril }\end{array}$ & $\begin{array}{c}\text { Peso } \\
\text { molecular } \\
\text { kDa }\end{array}$ \\
\hline 1 & 4,6 & 66,0 \\
2 & 4,4 & 45,0 \\
3 & 3,7 & 36,0 \\
4 & 8,3 & 29,0 \\
5 & 1,4 & 24,0 \\
6 & 4,3 & 20,0 \\
7 & 11,5 & 14,2 \\
8 & 12,2 & 6,5 \\
\hline
\end{tabular}

Figura 3. Electroferograma por Tricina-SDS PAGE de: a) Solución de proteínas de lactosuero previo a la hidrólisis; b)

Proteínas de lactosuero hidrolizadas durante 150 min (tiempo medio a la estabilización); c) Proteínas de lactosuero hidrolizadas durante 300 min. d)Marcador de proteínas utilizado como patrón. Fuente: elaboración propia. 
Al igual que en el trabajo de Ghosh et al. [17] para la hidrólisis de suero pasteurizado empleando Flavourzyme, previo a la hidrólisis, el análisis por tricina-SDS PAGE muestra dos bandas principales las cuales corresponden a las proteínas $\beta$-lactoglobulina $(18,3 \mathrm{kDa})$ y $\alpha$-lactoalbúmina $(13,5$ $\mathrm{kDa}$ ); las cuales están en mayor concentración en el lactosuero. Al transcurrir el tiempo de hidrólisis estas bandas se hicieron menos intensas y otras zonas descendentes se tornan oscuras indicando la presencia de especies proteicas menores a 6,5 kDa.
Evaluación de los hidrolizados de proteína como fuente de nitrógeno en la fermentación láctica de la lactosa.

El crecimiento de L. casei ATCC 393 en el precultivo utilizado para su activación previa a la fermentación, fue caracterizado en términos de densidad óptica y $\mathrm{UFC} / \mathrm{cm}^{3}$ (tabla 4), con el fin de estandarizar el tamaño del inóculo y conseguir una población entre $10^{6}$ y $10^{8} \mathrm{UFC} / \mathrm{cm}^{3}$; lo que garantiza que la bacteria se encuentre en su fase exponencial de crecimiento [23].

Tabla 4. Seguimiento de la concentración del precultivo mediante medición de (D.O.) $660 \mathrm{~nm}$ y recuento de UFC/ $\mathrm{cm}^{3}$, para L. casei ATCC 393.

\begin{tabular}{ccc}
\hline $\begin{array}{c}\text { Tiempo } \\
\text { [h] }\end{array}$ & $\begin{array}{c}\text { D.o.660 } \\
\text { nm }\end{array}$ & $\begin{array}{c}\text { Recuento } \\
{\left[\mathrm{UFC} / \mathrm{cm}^{3}\right]}\end{array}$ \\
\hline 0 & 0,001 & $6,0 \times 10^{7}$ \\
4 & 0,224 & $1,1 \times 10^{8}$ \\
8 & 0,757 & $4,0 \times 10^{8}$ \\
12 & 0,872 & $4,0 \times 10^{9}$ \\
\hline
\end{tabular}

Fuente: elaboración propia.

Se realizaron dos series de fermentaciones que partieron de inóculos con D.O. de 0,285 y 0,135, para el original y duplicado, respectivamente, teniendo así, en ambos casos, un inóculo añadido en la fase exponencial de crecimiento. Cabe resaltar que la mayor D.O. registrada para el precultivo de la prueba original, sugiere que la concentración de microorganismos añadida al medio de fermentación en este caso fue un poco mayor que la añadida en la segunda fermentación.

En la figura 4.a, se muestra el seguimiento al crecimiento microbiano en las pruebas de fermentación realizadas mediante recuento de UFC $/ \mathrm{cm}^{3}$, medición de D.O. (figuras 4.b y 4.c) y pH (figuras 4.d y 4.e). Se distinguen con claridad las fases de crecimiento del microorganismo en los 3 medios en estudio. En todos los casos la fase de adaptación fue $<4 \mathrm{~h}$ (tiempo de muestreo inicial) debido a la similitud entre el medio de precultivo y los medios de fermentación.

La fase de crecimiento exponencial tuvo una duración de $34 \mathrm{~h}$ para los medios con extracto de levadura al $1 \% p$ e hidrolizado al $1 \% p$, deteniéndose su crecimiento en una concentración microbiana de $2,1^{*} 10^{9} \mathrm{UFC} / \mathrm{cm}^{3}$ y $1,9^{*} 10^{9} \mathrm{UFC} /$ $\mathrm{cm}^{3}$, respectivamente, mientras que para el medio con hidrolizado al $7 \%$ p se presentó un crecimiento más lento, finalizando la fase exponencial a las $48 \mathrm{~h}$ con una concentración microbiana final de $9,5^{*} 10^{8} \mathrm{UFC} / \mathrm{cm}^{3}$.
El medio con hidrolizado al $7 \%$ p además de presentar el menor crecimiento microbiano, registró el pH más alto al finalizar las fermentaciones, con un valor de $4,5 \pm 0,1$, mientras que para los medios con hidrolizado al $1 \% p$ y extracto de levadura al $1 \% p$ el $\mathrm{pH}$ final fue $3,7 \pm 0,1$ y $3,4 \pm 0,0$, respectivamente. Dicha inhibición para el medio con hidrolizado al 7 $\% p$, podría presentarse por 2 razones principales: la alta concentración de cenizas (minerales) y la alta concentración de nitrógeno total en el medio. Los \% de ceniza y nitrógeno estimados en cada medio se presentan en la Tabla 5.

De la tabla anterior se observa una importante similitud en el contenido de ceniza y nitrógeno total paralosmediosconextractodelevaduraehidrolizado al $1 \% p$, lo cual justifica el comportamiento similar en cuanto a crecimiento microbiano y evolución del $\mathrm{pH}$ en las fermentaciones. Por otra parte, el \% de nitrógeno total para el medio con hidrolizado al 7 $\%$ es alto y superior en más de 2 veces al $\%$ de nitrógeno total del caldo MRS ( 0,28 \%p), medio de referencia usado para el crecimiento de bacterias del género Lactobacillus. Adicionalmente, en la literatura las máximas concentraciones de extracto de levadura reportadas en fermentaciones lácticas son del orden de $30 \mathrm{~g} / \mathrm{L}$, es decir, aproximadamente $0,3 \% p$ de nitrógeno total en el medio. Lo señalado anteriormente indicaría que el exceso de nitrógeno en el medio en mención podría haber afectado el desempeño de la fermentación. 
Tabla 5. Porcentajes de ceniza y nitrógeno total estimados en los medios de fermentación.

\begin{tabular}{cccc}
\hline Componente & $\begin{array}{c}\text { Medio con E. } \\
\text { levadura al 1\% }\end{array}$ & $\begin{array}{c}\text { Medio con } \\
\text { hidrolizado al 1\% }\end{array}$ & $\begin{array}{c}\text { Medio con } \\
\text { hidrolizado al 7\% }\end{array}$ \\
\hline Cenizas & $0,11 \% \mathrm{p} / \mathrm{p}$ & $0,10 \% \mathrm{p} / \mathrm{p}$ & $0,50 \% \mathrm{p} / \mathrm{p}$ \\
Nitrógeno total & $0,10 \% \mathrm{p} / \mathrm{p}$ & $0,093 \% \mathrm{p} / \mathrm{p}$ & $0,65 \% \mathrm{p} / \mathrm{p}$ \\
\hline
\end{tabular}
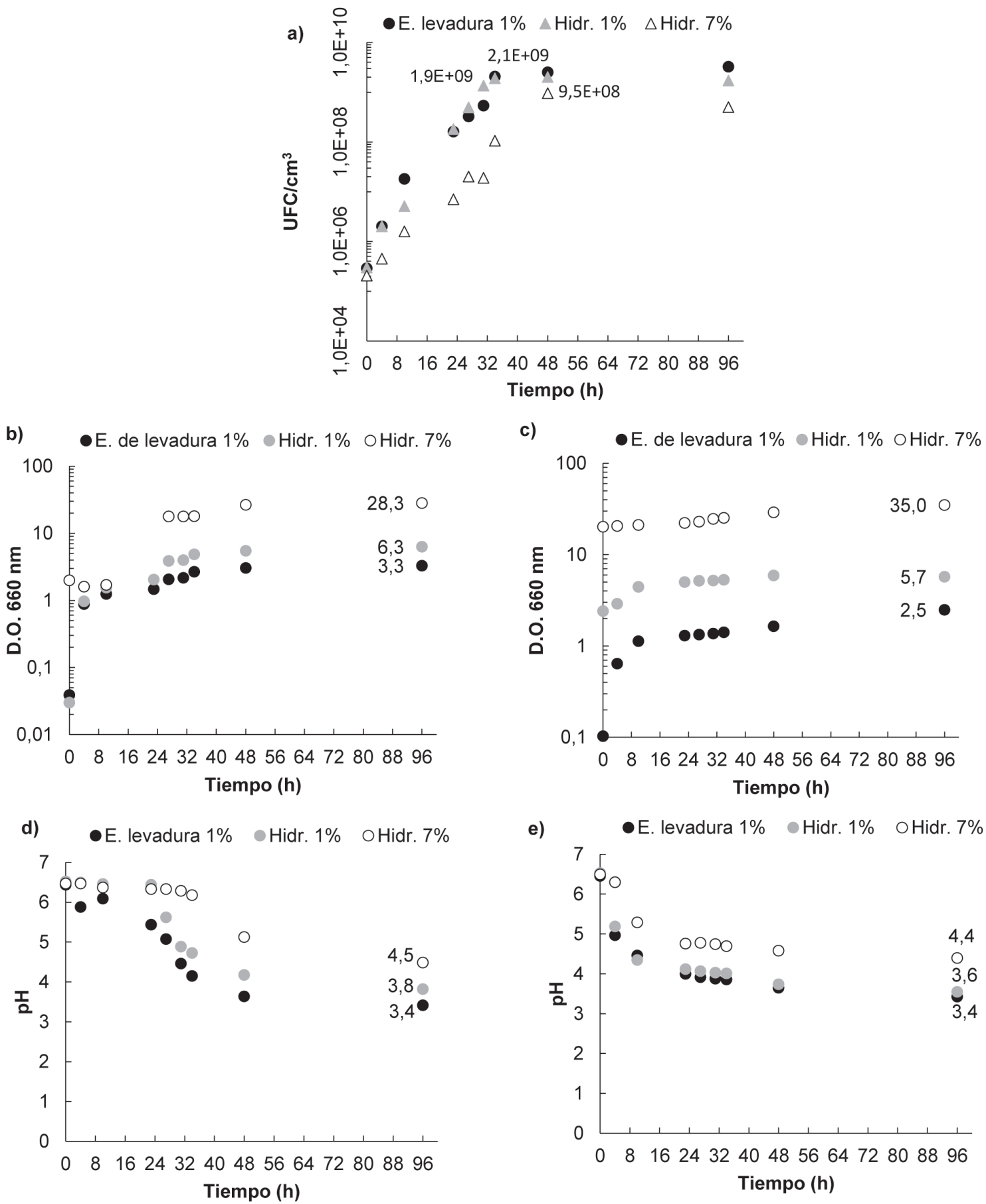

Figura 4. a) Curva de evolución de las UFC/ $\mathrm{cm}^{3}$; b) y c) D.O. $660 \mathrm{~nm}$ original y duplicado, respectivamente; c) y d) seguimiento al $\mathrm{pH}$ original y duplicado, respectivamente. Fuente: elaboración propia. 
Por otra parte, Castro [23], reporta un tiempo de cese en el crecimiento a las $28 \mathrm{~h}$ para $L$. casei ATCC 334, utilizando un medio a base de lactosuero desproteinizado, los mismos cofactores del presente estudio, extracto de levadura al $1 \% \mathrm{p} / \mathrm{v}$, un precultivo activado en caldo MRS y sin control de $\mathrm{pH}$. No obstante, la utilización de una cepa diferente, su activación en caldo MRS (medio de cultivo rico en compuestos nitrogenados como proteasa de peptona, extracto de carne, entre otros), junto con el aprovechamiento de otros nutrientes (principalmente nitrógenados) presentes en el lactosuero, pudo favorecer una mayor velocidad de crecimiento del microorganismo.

Por otra parte, la literatura indica que la especie L. casei presenta inhibición a $\mathrm{pH}<5$, aspecto confirmado en el presente trabajo y evidenciado en las figuras 4.d y 4.e, donde se aprecia un cese en el crecimiento a un $\mathrm{pH}$ de 3,$4 ; 3,8$ y 4,5 , para los medios con extracto de levadura al $1 \% p$, hidrolizado al $1 \% p$ e hidrolizado al 7 $\% p$, respectivamente. Es de apreciar que en la segunda serie de fermentaciones el descenso en el $\mathrm{pH}$ es más rápido en comparación a la primera fermentación, con lo cual se podría pensar que el haber añadido un inóculo con una menor concentración inicial de microorganismos (menor D.O.), favoreció la adaptación al medio de fermentación. De esta manera estudiar el efecto del tamaño del inóculo en los medios analizados permitiría determinar la concentración inicial de microorganismos más favorable.

En la figura 5 se muestra el ajuste lineal del Ln (N/No) [UFC/cm ${ }^{3}$ vs tiempo, realizado para la estimación de umáx , tal como se mencionó en la metodología, para las tres fuentes de nitrógeno estudiadas en la primera serie de fermentaciones. Los valores de $0,26 \mathrm{~h}^{-1} ; 0,25 \mathrm{~h}^{-1}$ obtenidos para los medios con extracto de levadura e hidrolizado de proteínas al $1 \% \mathrm{p}$, respectivamente, fueron similares entre sí y son acordes a los obtenidos por Ghaly \& Kamal [24] y Altiok et al. [25], quienes trabajaron con extracto de levadura y lactosuero, presentando una $\mu$ máx de $0,25 \mathrm{~h}^{-1}$ y $0,26 \mathrm{~h}^{-1}$, respectivamente. Esta similitud en la velocidad específica de crecimiento evidenciada para los medios de fermentación con extracto de levadura al $1 \%$ y con hidrolizado de proteína del lactosuero al $1 \%$ indican que el hidrolizado a esta concentración, en términos de crecimiento microbiano, representa una alternativa de interesante potencial. Por otra parte, la $\mu$ máx de $0,17 \mathrm{~h}^{-1}$ alcanzada para el medio con hidrolizado al $7 \%$ p muestra que el crecimiento pudo haberse ralentizado por exceso de nitrógeno en el medio. Adicionalmente, la determinación del ácido láctico inicial y final en el medio de fermentación junto con la concentración inicial y final de lactosa permitió el cálculo de los rendimientos y las productividades en los distintos medios; los resultados se muestran en la tabla 5 .

Se distinguen rendimientos muy similares para los medios con extracto de levadura e hidrolizado al $1 \% \mathrm{p} / \mathrm{p}$, mientras que para el medio con hidrolizado al $7 \% \mathrm{p} / \mathrm{p}$ presentó una reducción del $25 \%$. La mayor productividad alcanzada se registró para el medio con extracto de levadura comercial, sin embargo, la obtenida con el hidrolizado de proteína del lactosuero al $1 \% \mathrm{p} / \mathrm{p}$ se asemeja al de esta fuente de nitrógeno convencional; pero que tiene la ventaja de un menor costo para el proceso de fermentación. Castro [23] reporta un rendimiento de 0,64 $\mathrm{g}$ ác. láctico producido/g lactosa consumida y una productividad de 0,55 $g$ ác. láctico producido/g lactosa consumida, utilizando extracto de levadura al $1 \% \mathrm{p} / \mathrm{p}$ y un medio de fermentación con los mismos cofactores y fuente de carbono usados en el presente trabajo. Büyükkileci \& Harsa [26] obtuvieron una concentración final de ácido láctico de $46 \mathrm{~g} / \mathrm{dm}^{3}$ (rendimiento de 0,93 ) y una productividad de 1,87 $\mathrm{g} / \mathrm{dm}^{3} . \mathrm{h}$ durante $30 \mathrm{~h}$. Sin embargo, utilizaron carbonato de calcio como agente de control de $\mathrm{pH}$ lo cual evitó alcanzar el pH de inhibición del microorganismo, permitiendo prolongar la fase exponencial del microorganismo e inducir el consumo total de la lactosa presente en el medio. Se debe recordar que las soluciones preparadas presentan concentración inicial de ácido láctico ya que dichas proteínas fueron recuperadas de lactosueros ácidos, los cuales contienen una cantidad menor de ácido láctico. 

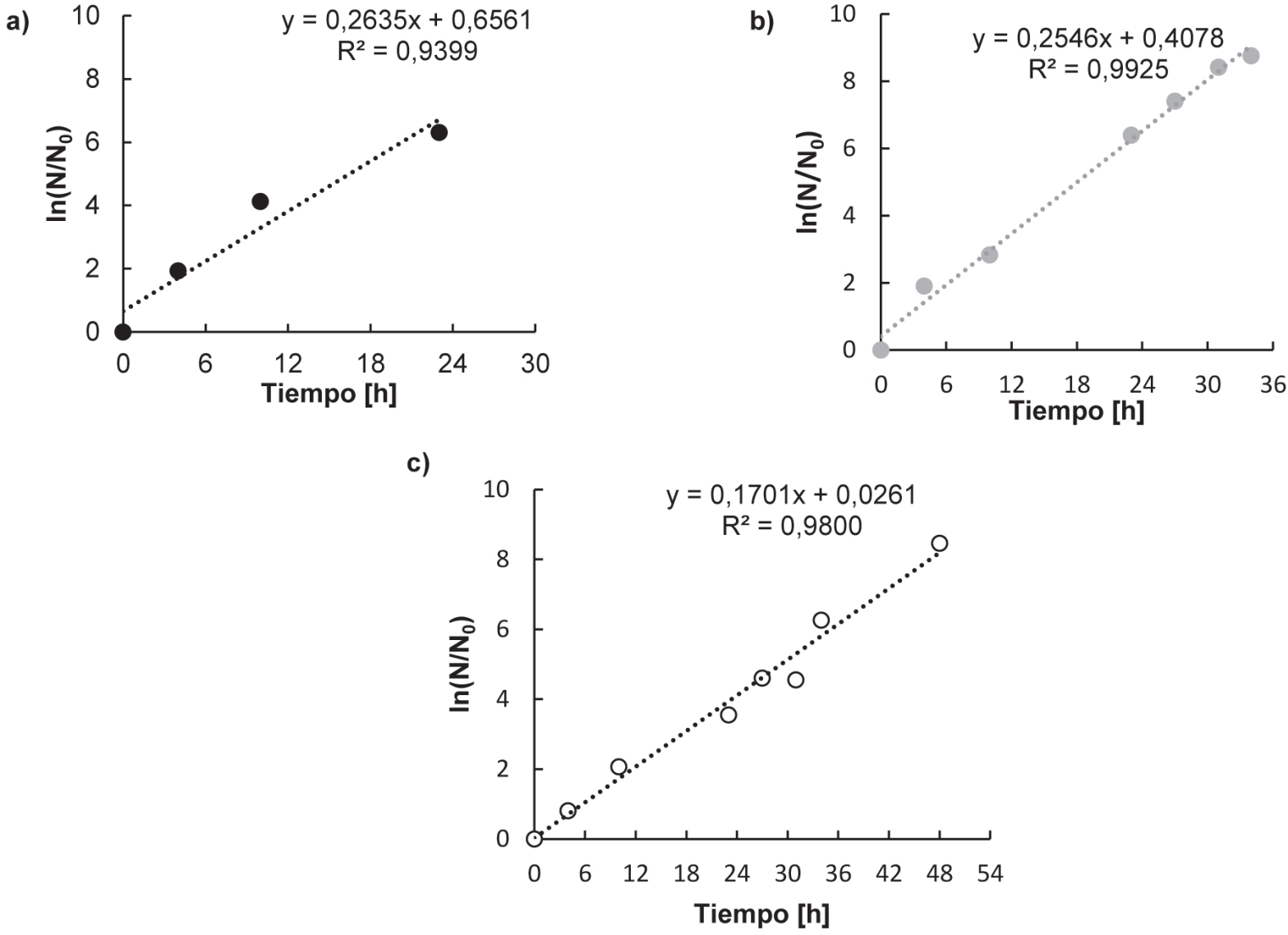

Figura 5. Determinación de la velocidad específica de crecimiento máxima ( $\mu$ máx) de Lactobacillus casei ATCC 393 utilizando como fuente de nitrógeno: a) Extracto de levadura al $1 \% \mathrm{p} / \mathrm{p}$, b) Hidrolizado al $1 \% \mathrm{p} / \mathrm{p}$ y c) Hidrolizado al $7 \%$ p/p. N [UFC/cm $\left.{ }^{3}\right]$ Fuente: elaboración propia.

Tabla 5. Determinación del rendimiento y la productividad de ácido láctico para los 3 medios, a las $27 \mathrm{~h}$ de fermentación.

\begin{tabular}{ccccccc}
\hline $\begin{array}{c}\text { Fuente de Nitrógeno } \\
\text { [\%p/p] }\end{array}$ & $\begin{array}{c}\mathbf{S}_{\mathbf{0}}[\mathbf{g} / \\
\left.\mathbf{d m}^{3}\right]\end{array}$ & $\begin{array}{c}\mathbf{S f} \\
{\left[\mathbf{g} / \mathbf{d m}^{3}\right]}\end{array}$ & $\begin{array}{c}\mathbf{P}_{0} \\
{\left[\mathbf{g} / \mathbf{d m}^{3}\right]}\end{array}$ & $\begin{array}{c}\mathbf{P f} \\
{\left[\mathbf{g} / \mathbf{d m}^{3}\right]}\end{array}$ & $\begin{array}{c}¥ \\
{[\mathbf{g} / \mathbf{g}]}\end{array}$ & $\begin{array}{c}\mathbf{P} \\
{\left[\mathbf{g} / \mathbf{d m}^{3} \cdot \mathbf{h}\right]}\end{array}$ \\
$\begin{array}{c}\text { Extracto de levadura } \\
\text { al 1\% }\end{array}$ & 42,87 & 26,07 & 1,02 & 14,12 & 0,78 & 0,41 \\
$\begin{array}{c}\text { Hidrolizado de proteína } \\
\text { al 1\% }\end{array}$ & 42,53 & 29,10 & 2,80 & 13,10 & 0,76 & 0,30 \\
$\begin{array}{c}\text { Hidrolizado de proteína } \\
\text { al 7\% }\end{array}$ & 40,52 & 30,55 & 3,60 & 8,89 & 0,53 & 0,18 \\
\hline
\end{tabular}

Fuente: elaboración propia.

$S_{0}$ y Sf concentración de lactosa inicial y final, respectivamente. $P_{0}$ y Pf: concentración de ácido láctico inicial y final, respectivamente; ¥: rendimiento; $P$ : productividad.

\section{Conclusiones}

Dentro del rango de trabajo estudiado, se determinaron las mejores condiciones para la hidrólisis de proteínas de lactosuero $(\mathrm{pH}$ de 10 y $60^{\circ} \mathrm{C}$ ) utilizando la enzima Gelzyme L500@, alcanzando un $\mathrm{DH}$ de $30 \%$ en $300 \mathrm{~min}$. Se pudo observar la desaparición progresiva de las proteínas y la formación de especies nitrogenadas de tamaño molecular menor a 6,5 kDa.

El uso de los hidrolizados como fuente de nitrógeno en las fermentaciones mostró similitudes 
en el desempeño de los medios con extracto de levadura al $1 \% p$ e hidrolizado de proteína al $1 \% \mathrm{p}$, en términos de crecimiento microbiano $\left(2,1 * 10^{9}\right.$ y $1,9 * 10^{9}$ UFC/cm ${ }^{3}$, rendimiento $(0,78$ y $0,76 \mathrm{~g} / \mathrm{g})$ y productividad $\left(0,41\right.$ y $\left.0,30 \mathrm{~g} / \mathrm{dm}^{3} . \mathrm{h}\right)$, respectivamente. Los medios con hidrolizado de proteína al $7 \%$ registraron menor crecimiento microbiano $\left(9,5^{*} 10^{8} \mathrm{UFC} / \mathrm{cm}^{3}\right)$, rendimiento $(0,53$ $\mathrm{g} / \mathrm{g}$ ) y productividad $\left(0,18 \mathrm{~g} / \mathrm{dm}^{3} . \mathrm{h}\right)$, lo cual podría asociarse a una inhibición por exceso de nitrógeno en este medio de fermentación. El presente estudio permitió mostrar el interesante potencial que tienen los hidrolizados de proteína de lactosuero para ser usada como fuente de nitrógeno de bajo costo en la fermentación láctica.

\section{Agradecimientos}

Los autores agradecen a la Universidad Industrial de Santander por la financiación de este trabajo mediante el proyecto interno VIE-UIS 9364 y al Sena C.A.S.A. Piedecuesta, Santander (Colombia) por la cooperación en el desarrollo de las actividades de investigación.

\section{Referencias bibliográficas}

[1] Hofvendahl K, Hahn-Hägerdal B. Factors affecting the fermentative lactic acid production from renewable resources. Enzyme Microb Technol. 2000;26(2-4):87-107. https://doi. org/10.1016/S0141-0229(99)00155-6(1)

[2] Departamento Administrativo Nacional de Estadística (DANE) (2012-2015). Encuesta Anual Manufacturera (EAM). Bogotá, Colombia; 2019.

[3] Garcia CA, Arrázola Paternina G, Durango AM. Producción de ácido láctico por vía biotecnológica. Temas Agrarios. 2010;15(2):926.

[4] Miller C, FosmerA, Rush B, McMullin T, Beacom $D$, Suominen P. Industrial Production of Lactic Acid. In: Comprehensive Biotechnology. Second Edition. Netherlands: Elsevier Inc.; 2011. p. 179-88. https://doi.org/10.1016/B9780-08-088504-9.00177-X.

[5] Mohseni J, Fazeli M, Lavasani AS. (2016). Effect of various parameters of carbon and nitrogen sources and environmental conditions on the growth of Lactobacillus Casei in the production of lactic acid. Global Journal of Medical Research: L Nutrition \& Science. 2016;16(2):67-73.
[6] Amrane A. Batch cultures of supplemented whey permeate using Lactobacillus helveticus: Unstructured model for biomass formation, substrate consumption and lactic acid production. Enzyme and Microbial Technology. 2001;28(9-10):827-34. https:// doi.org/10.1016/S0141-0229(01)00341-6.

[7] SernaL,RodriguezA.Producciónbiotecnológica de ácido láctico: Estado del arte. Ciencia y Tecnología Alimentaria. 2005;5(1):54-65. https://doi.org/10.1080/11358120509487672.

[8] Panesar PS, Kennedy JF, Knill CJ, Kosseva M. Production of $\mathrm{L}(+)$ Lactic Acid using Lactobacillus casei from Whey. Brazilian Archives of Biology and Technology. 2010;53(1):219-26. https://doi.org/10.1590/ S1516-89132010000100027.

[9] Nancib N, Nancib A, Boudjelal A, Benslimane C, Blanchard F, Boudrant J. The effect of supplementation by different nitrogen sources on the production of lactic acid from date juice by Lactobacillus casei subsp. rhamnosus. Bioresource Technology. 2001;78(2):149-53.https://doi.org/10.1016/ S0960-8524(01)00009-8.

[10] Morr CV, Ha EYW. Whey protein concentrates and isolates: Processing and functional properties. Critical Reviews in Food Science and Nutrition. 1993;33(6):431-76. https://doi. org/10.1080/10408399309527643.

[11] Velásquez J, Giraldo G, Padilla L, Giraldo Y. Crecimiento de lactobacillus casei ssp casei ATCC 393 en suero clarificado. Biotecnología en el Sector Agropecuario y Agroindustrial. 2015;13(1):19-27. http://www.scielo.org.co/ scielo. php?script=sci_arttext\&pid=S169235612015000100003\&lang=pt.

[12]Vázquez Puente F, Villegas Arroyo G, Mosqueda Frías P. Precipitación de proteínas lactoséricas en función de la acidez, temperatura y tiempo, de suero producido en Comonfort, Guanajuato, México. Revista Venezolana de Ciencia y Tecnología de Alimentos. 2010;1(2):157-69.

[13] Coelho M, Silva M, Silva V, De Souza M, Lopes C, Afonso W. Analysis of whey protein hydrolysates: Peptide profile and ACE inhibitory activity. Brazilian Journal of Pharmaceutical Sciences. 2012;48(4):747-57. https://doi. org/10.1590/S1984-82502012000400019.

[14] Shu G, Zhang Q, Chen H, Wan H, Li H. Effect of five proteases including alcalase, flavourzyme, papain, proteinase $\mathrm{k}$ and trypsin 
on antioxidative activities of casein hydrolysate from goat milk. Acta Universitatis Cibiniensis Series E: Food Technology. 2015;19(2):65-74. https://doi.org/10.1515/aucft-2015-0015.

[15]Adler-Nissen J. Enzymic hydrolysis of food proteins. New York, Unites States: Elsevier Applied Science Publishers; 1986.

[16] Spellman D, McEvoy E, O'Cuinn G, FitzGerald RJ. Proteinase and exopeptidase hydrolysis of whey protein: Comparison of the TNBS, OPA and $\mathrm{pH}$ stat methods for quantification of degree of hydrolysis. International Dairy Journal. 2003;13(6):447-53. https://doi. org/10.1016/S0958-6946(03)00053-0.

[17] Ghosh BC, Prasad LN, Saha NP. Enzymatic hydrolysis of whey and its analysis. Journal of Food Science and Technology. 2017;54(6):1476-83. https://doi.org/10.1007/ s13197-017-2574-z.

[18]Perea A, Ugalde U, Rodríguez I, Serra JL. Preparation and characterization of whey protein hydrolysates: Applications in industrial whey bioconversion processes. Enzyme and Microbial Technology. 1993;15(5):418$23 . \quad$ https://doi.org/10.1016/01410229(93)90129-P.

[19] Galvão CMA, Silva AFS, Custódio MF, Monti R, Giordano RDLC. Controlled hydrolysis of cheese whey proteins using trypsin and a-chymotrypsin. In: Davison BH, McMillan J, Finkelstein M. (eds). Twenty-Second Symposium on Biotechnology for Fuels and Chemicals. United States: Humana Press; 2001. p. 761-776. https://doi.org/10.1385/ ABAB:91-93:1-9:761.

[20] Prieto C. Diseño y optimización de un reactor de membrana discontinuo para la hidrólisis enzimática de proteínas. (Tesis de doctorado). Granada, España: Universidad De Granada; 2007.

[21]Zheng $\mathrm{H}$, Shen X, Bu G, Luo Y. Effects of pH, temperature and enzyme-to-substrate ratio on the antigenicity of whey protein hydrolysates prepared by Alcalase. International Dairy Journal. 2008;18(10-11):1028-33. https://doi. org/10.1016/j.idairyj.2008.05.002.

[22] Polaina J, MacCabe AP. Industrial Enzymes: Structure, Function and Applications. The Netherlands: Springer; 2007. https://doi. org/10.1007/1-4020-5377-0.

[23] Castro A. Caracterización del proceso de obtención y separación de ácido láctico a partir de la fermentación de suero lácteo utilizando la tecnología de membranas. México: Universidad Autónoma De Querétaro; 2011.

[24] Ghaly AE, Kamal MA. Submerged yeast fermentation of acid cheese whey for protein production and pollution potential reduction. Water Research. 2004;38:631-44. https://doi. org/10.1016/j.watres.2003.10.019.

[25] Altıok D, Tokatl F, Harsa S. Kinetic modelling of lactic acid production from whey by Lactobacillus casei (NRRL B-441). Journal of Chemical Technology \& Biotechnology. 2006;82(May):1115-21. https://doi. org/10.1002/jctb.

[26] Büyükkileci AO, Harsa $S$. Batch production of $\mathrm{L}(+)$ lactic acid from whey by Lactobacillus casei (NRRL B-441). Journal of Chemical Technology and Biotechnology. 2004;79(9):1036-40. https://doi.org/10.1002/jctb.1094 